\title{
Systemic Lupus Erythematosus (Sle) with Diffuse Proliferative Lupus Nephritis and Pulmonary Alveolar Hemorrhage with Secondary Herpes Zoster: A Case Report
}

Bhupen Barman ${ }^{1}$, Arvind Nongpiur², Vandana Raphael ${ }^{3}$, Sameer Joshi ${ }^{4}$, Tony Ete $^{5}$

${ }^{1}$ Associate Professor, Department of Medicine, North Eastern Indira Gandhi Regional Institute of Health and Medical Sciences, Shillong

${ }^{2}$ Assistant Professor, Department of Psychiatry, North Eastern Indira Gandhi Regional Institute of Health and Medical Sciences, Shillong

${ }^{3}$ Professor and HOD, Department of Pathology, North Eastern Indira Gandhi Regional Institute of Health and Medical Sciences, Shillong

${ }^{4}$ Post Graduate Trainee, Department of Medicine, North Eastern Indira Gandhi Regional Institute of Health and Medical Sciences, Shillong

${ }^{5}$ Senior Resident, Department of Cardiology, North Eastern Indira Gandhi Regional Institute of Health and Medical Sciences, Shillong

Received: February 24, 2017; Accepted: April 19, 2017; Published: June 09, 2017

*Corresponding author: Dr Tony Ete MBBS MD, Senior Resident, Department of Cardiology, North Eastern Indira Gandhi Regional Institute of Health and Medical Sciences, Shillong, E-mail: tonyete14@gmail.com

\begin{abstract}
Diffuse alveolar hemorrhage is a rare but serious pulmonary manifestation of systemic lupus erythematosus that may occur at some point during the course of disease. Pleuropulmonary complication of SLE that ranges from pleuritic pain to catastrophic alveolar hemorrhage can occur during the course of illness in $50 \%$ to $70 \%$ of affected individuals. A high index of suspicion is needed in patients of SLE with progressive clinical deterioration. An aggressive diagnostic approach and prompt immunosuppressive treatment is important to improve survival which otherwise carries a very high mortality rate. Here we describe a case of Systemic Lupus Erythematosus complicated by diffuse alveolar hemorrhage and herpes zoster infection with full recovery after intensive immunosuppressive therapy.
\end{abstract}

Keywords: Systemic Lupus erythematosus; Alveolar hemorrhage; Lupus nephritis; Herpes zoster

\section{Introduction}

Systemic Lupus Erythematosus (SLE) is the prototypic autoimmune disease characterized by the production of auto antibodies to components of the cell nucleus in association with diverse clinical manifestations encompassing almost all organ systems [1]. The pleuropulmonary complication of SLE that ranged from mild pleuritic pain to catastrophic alveolar hemorrhage can occur at some point during the course of illness in $50 \%$ to $70 \%$ of affected individuals [2]. Alveolar hemorrhage usually occurs in patients with a known history of SLE, high titres of anti-DNA antibodies and lupus nephritis. We report a case of a 23 year old female with lupus nephritis which was later complicated by diffuse alveolar hemorrhage followed by herpetic zoster infection. The patient was successfully treated with pulse methyleprednisolone followed by pulse cyclophosphamide therapy and presently doing well in follow up.

\section{Case summary}

fA 23 year old female was admitted to our hospital because of dyspnoea, anemia and renal failure. The patient had been apparently normal one month prior to the admission, when mild dyspnea and easy fatigability developed. She had consulted a local physician and was treated with a course of oral antibiotic without much improvement and was later referred to our hospital. On evaluation, she complained of progressive fatigue, shortness of breath for last one month and followed by decreased urination and bilateral leg swelling for last five days. There was no cough, chest pain, fever, hemoptysis, night sweats, chills, headache, visual loss, dry eyes, dry mouths or joint pain. She had no recent 


\begin{tabular}{|c|c|c|c|}
\hline \multicolumn{4}{|l|}{ Table } \\
\hline Variable & Reference range (adults) & On admission & On follow up (after one month) \\
\hline Hematocrit (\%) & $41.0-53.0$ & 26.7 & 33.2 \\
\hline Hemoglobin (g/dl) & $13.5-17.5$ & 8.5 & 10.7 \\
\hline White cell count (per $\mathrm{mm}^{3}$ ) & $4500-11,000$ & 10000 & 6500 \\
\hline \multicolumn{4}{|l|}{ Differential count (\%) } \\
\hline Neutrophils & $40-70$ & 81 & 66 \\
\hline Monocytes & $4-11$ & 01 & 03 \\
\hline Eosinophils & $0-8$ & 00 & 04 \\
\hline Basophils & $0-3$ & 00 & 01 \\
\hline Platelet count (per $\mathrm{mm}^{3}$ ) & $150,000-400,000$ & 220,000 & 365,000 \\
\hline Mean corpuscular volume $\left(\mu \mathrm{m}^{3}\right)$ & $80-100$ & 80 & 86 \\
\hline Erythrocyte count (per mm ${ }^{3}$ ) & $4,500,000-5,900,000$ & $3,900,000$ & $4,700,000$ \\
\hline $\begin{array}{l}\text { Mean corpuscular hemoglobin } \\
\text { concentration }(\mathrm{g} / \mathrm{dl})\end{array}$ & $31.0-37.0$ & 31 & 35 \\
\hline $\begin{array}{l}\text { Erythrocyte sedimentation rate }(\mathrm{mm} / \\
\mathrm{hr})\end{array}$ & $0-17$ & 76 & 38 \\
\hline Blood urea nitrogen $(\mathrm{mg} / \mathrm{dl})$ & $8-25$ & 62 & 34 \\
\hline Serum creatinine (mg/dl) & $0.60-1.50$ & 2.1 & 1.6 \\
\hline Sodium (mmol/liter) & $135-145$ & 133 & 142 \\
\hline Potassium (mmol/liter) & $3.4-4.8$ & 3.78 & 4.3 \\
\hline Chloride (mmol/liter) & $100-108$ & 101 & 103 \\
\hline $\begin{array}{l}\text { Serum Billirubin }(\mathrm{mg} / \mathrm{dl}) \\
\text { Total } \\
\text { Direct }\end{array}$ & $\begin{array}{c}0-1.0 \\
0-0.4\end{array}$ & $\begin{array}{c}0.5 \\
0.1\end{array}$ & $\begin{array}{c}0.4 \\
0.1\end{array}$ \\
\hline Alanine aminotransferase (U/liter) & $10-55$ & 33 & 25 \\
\hline Aspartate aminotransferase (U/liter) & $10-44$ & 30 & 22 \\
\hline $\begin{array}{c}\text { Protein }(\mathrm{g} / \mathrm{dl}) \\
\text { Total } \\
\text { Albumin } \\
\text { Globulin }\end{array}$ & $\begin{array}{l}6.0-8.3 \\
3.3-5.0 \\
2.3-4.1\end{array}$ & $\begin{array}{l}4.7 \\
1.8 \\
2.9\end{array}$ & $\begin{array}{l}6.0 \\
3.4 \\
2.6\end{array}$ \\
\hline HIV-1 and HIV-2 antibodies & & Non reactive & Not done \\
\hline HBsAg, Anti-HCV antibody & & Negative & Not done \\
\hline Antinuclear antibodies & & $\begin{array}{l}\text { Positive at 1:2560 dilution, homogenous } \\
\text { pattern }\end{array}$ & Not done \\
\hline Anti ds-DNA & & Positive at 1:320 titer & Not done \\
\hline ANCA & & Negative & Not done \\
\hline C3 (mg/dl) & $86-184$ & 42 & 64 \\
\hline $\mathrm{C} 4(\mathrm{mg} / \mathrm{dl})$ & $16-38$ & 4 & 12 \\
\hline $\begin{array}{c}\text { Urine } \\
\text { PH } \\
\text { Specific gravity } \\
\text { Color } \\
\text { Turbidity } \\
\text { Screening-dipstick test } \\
\text { Glucose } \\
\text { Albumin } \\
\text { Occult blood } \\
\text { Urobilinogen } \\
\text { White cells } \\
\text { Sediment } \\
\text { Red cells (per high power field) } \\
\text { Bacteria(per high power field) } \\
\text { Hyaline cast(per low power field) } \\
\text { Granular cast(per low power field) } \\
24 \text { urinary protein (mg/24 hours) }\end{array}$ & $\begin{array}{l}5.0-9.0 \\
1.001-1.035 \\
\text { Yellow } \\
\text { Clear } \\
\\
\text { Negative } \\
\text { Negative } \\
\text { Negative } \\
\text { Negative } \\
\text { Negative } \\
0-2 \\
\\
\text { Negative } \\
0-5 \\
\text { None }\end{array}$ & $\begin{array}{c}5.5 \\
1.010 \\
\text { Yellow } \\
\text { Clear } \\
\\
\text { Negative } \\
3+ \\
\text { Negative } \\
\text { Negative } \\
\text { Negative } \\
\\
\text { Nil } \\
\text { Negative } \\
2 \\
\text { None } \\
4546\end{array}$ & $\begin{array}{l}5.7 \\
1.007 \\
\text { Yellow } \\
\text { Clear } \\
\\
\text { Negative } \\
1+ \\
\text { Negative } \\
\text { Negative } \\
\text { Negative } \\
\\
\text { Nil } \\
\text { Negative } \\
2 \\
\text { None } \\
2150\end{array}$ \\
\hline
\end{tabular}

Citation: Tony Ete, Bhupen Barman, et.al. (2017) Systemic Lupus Erythematosus (Sle) with Diffuse Proliferative Lupus Nephritis and Page 2 of 4 Pulmonary Alveolar Hemorrhage with Secondary Herpes Zoster: A Case Report. J Rheumatol Arthritic Dis 2(3)1-4. 
history of travel, contact with sick persons, blood transfusions or previous surgery. There was no history of smoking, alcohol or use of illicit drugs. On examination, temperature was 36.70C, blood pressure was 180/90 $\mathrm{mmHg}$, pulse rate was 87 beats per minute, respiratory rate was 20 beats per minute and oxygen saturation was $92 \%$ while she was breathing ambient air. Her skin and conjunctivae were pale along with bilateral edema of her legs and bilateral basal crackles in her lungs. The remainder of the examination was normal. Blood investigations revealed mild anemia, altered renal function with normal liver function test and coagulation profile (Table 1). Routine examination of urine revealed $3+$ protinuria and 24 hours protein was 4546 $\mathrm{mg} / 24$ hours. Further testing for hepatitis B and C viruses, HIV and rheumatoid factor were negative. She was treated with intravenous furosemide ( $40 \mathrm{mg}$ twice daily), continuous infusion of nitroglycerine, prophylactic intravenous ceftriaxone $(1 \mathrm{gm}$ twice daily) and oxygen supplementation. A chest radiograph showed slight cardiomegally and mild bilateral pleural effusion. Transthoracic cardiac echocardiography revealed normal global cardiac function with mild pericardial effusion. An ultrasonography of abdomen showed moderate ascites with renal parenchymal changes. Preliminary autoimmune test result showed positive antinuclear antibody (ANA) at 1:2560 titer and had a homogeneous pattern. The titer for antibodies to doublestranded DNA was positive at 1:320. Patient was diagnosed as a case of Systemic Luspus Erythematosus (ACR Criteria). Testing for ANCA, antibodies to proteinase 3 and myeloperoxidase, and Goodpasture's antigen (NC1 domain of the $\alpha 3$ chain of type IV collagen) were negative. The levels of $\mathrm{C} 3$ and $\mathrm{C} 4$ were $42 \mathrm{mg} /$ $\mathrm{dL}$ (normal $86-184 \mathrm{mg} / \mathrm{dL}$ ) and $4 \mathrm{mg} / \mathrm{dL}$ (normal 16-38mg/dL), respectively. A renal biopsy was performed on the third day of hospital stay (Figure 1A-1D).

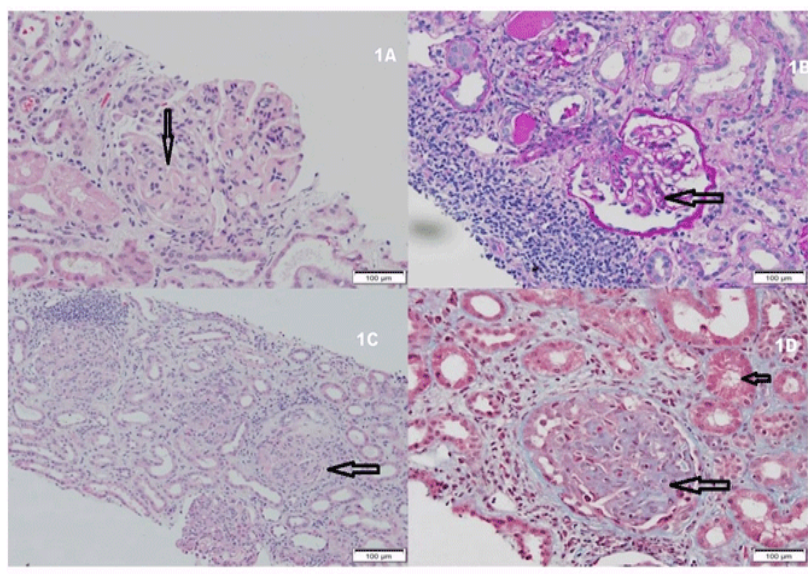

Figure 1:

Examination of renal cortical tissue by light microscopy showed 13 glomeruli with adjacent corticomedullary units. 1/13 glomeruli show global sclerosis. Other glomeruli showed glomerular enlargement with increased mesengial hypercellularity and mesengial deposits. Some of the glomeruli showed endocapillary thickening forming lobular accentuation with wire loop thickening. Few glomeruli showed segmental necrosis with presence of hyaline thrombi. There is dense lymphoplasmacytic lymphoid aggregate around the glomeruli. The renal tubules and interstitium were also abnormal with tubular atrophy and interstitial fibrosis and showed acute on chronic inflammatory cell infiltrates. Immunofluorescence staining of the frozen tissue showed strong staining with IgG, IgA and C3 in granular pattern in the mesangium and along the GBM, with focal confluence of deposits mirroring the wire loop appearance seen on light microscopy. Based on the involvement and characteristics of glomeruli, the disease was classified as a diffuse proliferative and sclerosing lupus nephritis, with both active and chronic lesions, referred to as class IV-G (A/C) with activity index score of $11 / 24$ and chronicity index of $4 / 12$. Based on clinical and laboratory findings, a working diagnosis of SLE was made and she was started on oral steroid (tablet prednisolone $50 \mathrm{mg} /$ day) with tablet mycofenolate mofetil (500 mg thrice daily) and other supportive medications. She was doing well in next couple of days and then she developed frequent hemoptysis. Axial and coronal Computed Tomography (CT) of the chest showed patchy areas of ground- glass opacities with few thickened interlobular septae. The opacities show perihilar predominance with relative sparing of the apices and costophrenic angles. Bilateral pleural effusions with pericardial effusion are also seen (Figure 2A and 2B).

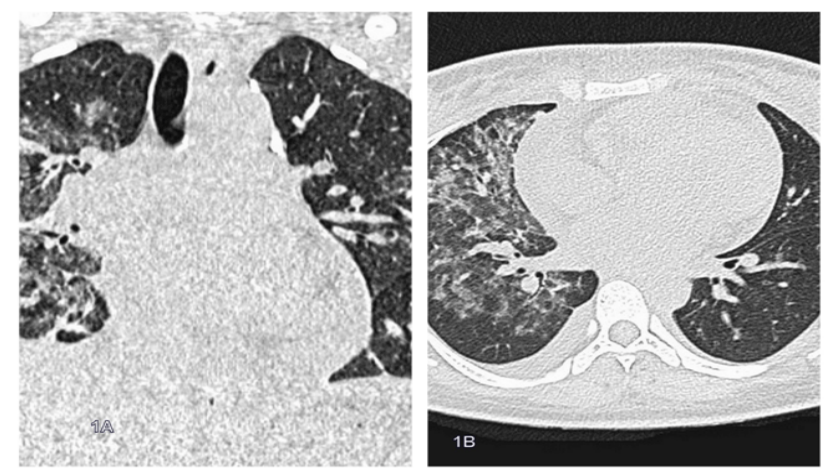

Figure 2:

She was started with pulse dose of intravenous methyleprednisolone $1 \mathrm{gm}$ daily for 3 days followed by pulse therapy of intravenous cyclophosphamide (750 mg monthly). The patient did well on follow up and completed three doses of pulse cyclophophamide therapy. Her renal functions improved, edema disappeared. After second pulse of cyclophophamide therapy she developed multiple grouped and confluent vesicles and bullae distributed in a linear fashion involving C8 and T1 dermatome on right upper limb suggestive of diffuse herpetic eruption (Figure 3 ). Dermatology consultation was done and advised for oral famcyclovir therapy (500 mg thrice daily for 10 days) and she recovered completely. She maintained her improvement on pulse cyclophophamide, oral steroid, ACE inhibitor, atorvastatin. 

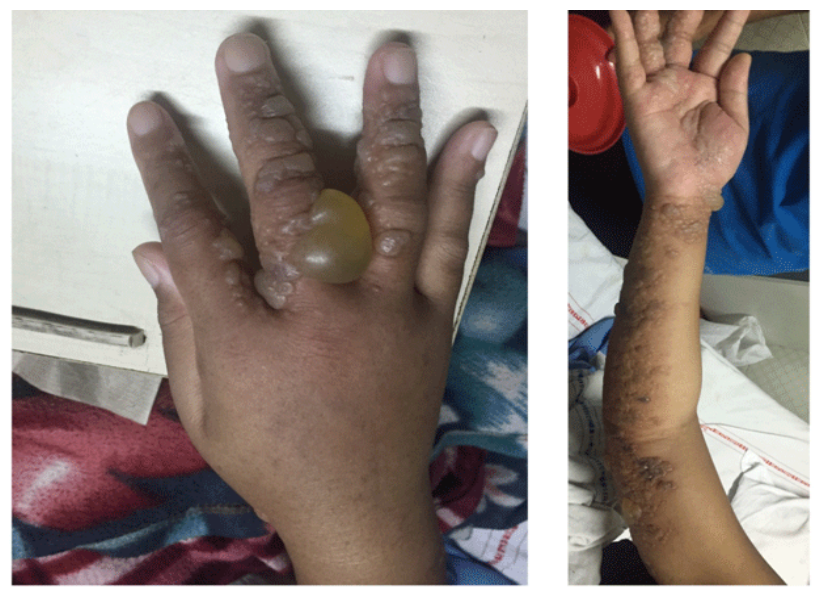

Figure 3:

\section{Discussion}

When we considered nephrotic syndrome with diffuse alveolar hemorrhage, a general category of pulmonary renal syndrome was kept as primary diagnosis. Since Antineutrophil cytoplasmic antibodies (ANCA) associated vasculitis is the single most common cause of this pulmonary related syndrome, diagnosis was considered in the present case. However, ANCA negativity and the absence of systemic features such as fever, myalgia, arthralgia and skin lesions (palpable purpura and leukocytoclastic vasculitis) almost ruled out ANCA associated vasculitis. SLE with involvement both kidney and lungs, albeit later, has lesser involvement (0.5-5\%) had serious consideration in the present patient [3].

Pleuropulmonary involvement in SLE are characterized by pleuritis and pleural effusions, acute pneumonitis, pulmonary embolism, diffuse alveolar hemorrhage, pulmonary vasculitis, pulmonary hypertension, diaphragmatic weakness and bronchiolitis [2]. Interstitial Lung Disease may be the presenting feature of SLE [4]. Lung hemorrhage in patient with SLE is nearly always associated with lupus nephritis, as in this case. The lung lesions may manifest as bland alveolar hemorrhage or a localized inflammatory pulmonary capillaritis, with bland lesions usually predominating over the inflammatory lesions. This patient had evidence of both hemorrhage and inflammation. Other features that this patient had that were compatible with SLE were protinuria, polyserosities, hypocomplementemia, positive tests for anti-nuclear antibody and ds-DNA. Arthritis, arthralgia, neuropsychiatric involvement and thrombocytopenia can also be present in SLE but were not prominent in this patient. There are other numerous possibilities of pulmonary renal syndrome such as thromboembolic disease, uraemic pneumonitis, infectious diseases (HIV, Disseminated cryptococcosis, Legionnaires' disease, and sepsis), other connective tissue diseases and vasculitis, IgA nephropathy, hemolytic uremic syndrome, acute tubular necrosis and hypersensitivity to drugs like nitrofurantoin, penicillamine, hydralazine, propylthiouracil, or phenytoin [3]. Diffuse alveolar hemorrhage, first described by Osler in
1904 [5], is a rare but one of the most devastating pulmonary complication affecting $<2 \%$ of SLE patients. The pathogenesis of this uncommon condition is presumed to be immune-complex mediated, however, role of infection cannot be ruled out. Acute lupus pneumonitis (ALP), an acute pulmonary complication of SLE is often confused with DAH both by clinical and imaging studies. Pulmonary capillaritis which is a hallmark of DAH has not been described in ALP and progression to chronic interstitial lung disease which is a feature of ALP has not been reported for DAH. ALP can be a presenting manifestation of SLE and it is not necessarily associated with renal involvement. Herpes zoster is a distinctive syndrome caused by reactivation of varicella zoster virus characterized by painful blistering skin eruption along one or more dermatomal distribution [6]. The risk of herpes zoster in SLE patients varies from 13.5 to $70 \%$ in different case series and the risk is often mediated by abnormal T-cell cytotoxicity which is often aggravated by simultaneous use of steroids and immunosuppressant's $[7,8]$. Our case presented with herpes zoster along the distribution of C8 and T1 on right upper limb and she responded well to oral famcyclovir therapy with complete resolution of skin lesion.

\section{Conclusion}

Diffuse alveolar hemorrhage is a rare but potentially lethal pulmonary complication of SLE. Early clinical suspicion and serologic tests are crucial for determination of diagnosis, prognosis and the best course of therapy such as intensive corticosteroid and immunosuppressive treatment.

\section{References}

1. Kakati S, Teronpi R, Barman B. Frequency, pattern and determinants of flare in systemic lupus erythematosus: A study from North East India. The Egyptian Rheumatologist.2015;37(4):S55-S59.

2. Zamora MR, Warner ML, Tuder R, Schwarz MI. Diffuse alveolar hemorrhage and systemic lupus erythematosus. Clinical presentation, histology, survival, and outcome. Medicine (Baltimore). 1997;76(3):192-202.

3. Glassock RJ, Khorashadi L, Kushner YB. Case records of the Massachusetts General Hospital. Case 32-2012. A 35-year-old man with respiratory and renal failure. N Engl J Med. 2012, 18;367(16):15401553.

4. Mondal S, Ete T, Chakraborty A, Nag A, Sarkar S, et al. Interstitial Lung Disease as Presenting Feature of SLE. JCR. 2014;4:85-87.

5. Osler W. On the visceral manifestations of the erythema group of skin diseases.1904. Am J Med Sci. 2009;338(5):396-408.

6. Matthay RA, Schwarz MI, Petty TL, Stanford RE, Gupta RC, et al. Pulmonary manifestations of systemic lupus erythematosus: review of twelve cases of acute lupus pneumonitis. Medicine (Baltimore). 1975;54(5):397-409.

7. Chakravarty EF, Michaud K, Katz RS, Wolfe F. Increased Incidence of Herpes Zoster Among Patients with Systemic Lupus Erythematosus. [abstract] Arthritis Rheum. 2012;64(Suppl 10):605.

8. Sayeeda A, Al Arfaj H, Khalil N, Al Arfaj AS. Herpes Zoster Infections in SLE in a University Hospital in Saudi Arabia: Risk Factors and Outcomes. Autoimmune Dis. 2010;13;2011:174891. 